\title{
Malignant pleural mesothelioma cells resist anoikis as quiescent pluricellular aggregates
}

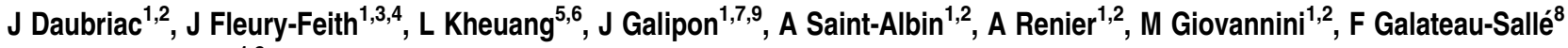 \\ and M-C Jaurand ${ }^{\star, 1,2}$
}

\begin{abstract}
Pleural fluid accumulation is a frequent clinical observation in diffuse malignant pleural mesothelioma (MPM). The cytological analysis of pleural fluid often reveals the presence of free spheroid aggregates of malignant cells, giving rise to the question of the ability of non-adherent tumor cells to resist the loss of anchorage-induced apoptosis (termed as anoikis), and to develop new tumor foci in the pleural cavity. Here, we show that MPM cells cultured under non-adherent conditions form well-organized aggregates composed of viable cells, which progressively enter in $\mathrm{G}_{0}$. Although the PI3K/Akt, ERK and SAPK/JNK signaling pathways are activated in adherent MPM cells, loss of anchorage results in the inactivation of these pathways. By comparison, we show that the non-tumoral mesothelial cells MeT-5A enter anoikis in an SAPK/JNK-, Bim- and caspase-9-dependent pathway. The survival of MPM cells can be reversed by activating SAPK/JNK with anisomycin, according to a Bim-dependent mitochondrial pathway. Finally, our findings show that impairment of cell aggregation activates SAPK/JNK and Bim and induces anoikis. Our results underline the importance of intercellular contacts in the anoikis resistance of MPM cells.
\end{abstract}

Cell Death and Differentiation (2009) 16, 1146-1155; doi:10.1038/cdd.2009.32; published online 3 April 2009

Malignant pleural mesothelioma (MPM) is a severe disease related primarily to asbestos exposure. This highly aggressive form of cancer does not respond to standard therapy. ${ }^{1}$ MPM progresses locally by invading pleural space and interlobular fissures, and encasing contiguous intrathoracic organs by coalescing on the visceral and parietal pleura into plaques and nodules. ${ }^{2}$ Pleural fluid accumulation is a frequent clinical sign of this disease. The cytological analysis of the pleural fluids generally reveals the presence of free spheroidal aggregates of MPM cells, which are strongly linked to malignancy. ${ }^{3,4}$ These observations suggest that free aggregates of MPM cells have a propensity to survive in the pleural fluid; yet, there has been very little research to date into the mechanisms allowing them to do so.

Although several apoptosis-resistance mechanisms in adherent (Adh) MPM cells have been reported, it is not known whether they are induced in free aggregates of MPM cells. Anoikis is a form of apoptosis induced by loss of matricial anchorage. Acquisition of resistance to anoikis, generated by the disruption of the anchorage-mediated survival mechanisms, contributes significantly to malignancy. ${ }^{5}$ This mechanism appears to be dependent on the cell systems. In several cell types, PI3K/Akt and ERK signaling pathways have been shown to be involved in this process. In squamous cell carcinoma, HGF mediates anoikis resistance through the activation of Akt and ERK. ${ }^{6}$ In the same vein, MCF10A human mammary cell line resistance to anoikis is observed following the expression of a constitutively active Akt-1, whereas Raf activation or cell cycle arrest protects cells through ERK activation. ${ }^{7,8}$ Although Src activation induces Akt-mediated anoikis resistance in human colon tumor and osteosarco$\mathrm{ma},{ }^{9,10}$ Src protects lung adenocarcinoma cells from anoikis through an Akt and ERK-independent/Pyk2-dependent pathway. ${ }^{11}$ By contrast, Pyk2 activation induces anoikis in osteocytes by activating one of their downstream targets, SAPK/JNK. ${ }^{12}$ SAPK/JNK has also been described as mediating anoikis in endothelial cells or during embryonic drosophila development. ${ }^{13,14}$

Cultured MPM cells are known to be highly resistant to apoptosis when studied under Adh conditions. ${ }^{15}$ This property has been attributed to the expression of antiapoptotic Bcl-2 proteins, $\mathrm{Bcl}-\mathrm{x}_{\mathrm{L}}$ and $\mathrm{Mcl}-1$, suggesting a defective mitochondrial control of apoptosis in mesothelioma. ${ }^{16}$ In upstream signaling, the deregulation of the mitochondrial control machinery has been attributed to the activation of survival $\mathrm{PI}$ KK/Akt or ERK pathways. PI3K/Akt involvement is based, first, on the finding that MPM often expresses elevated Akt activity and that high levels of Akt are associated with drug resistance, and, second, on experiments showing that Akt inhibition in MPM cells induces apoptosis. ${ }^{17-20}$ In addition,

${ }^{1}$ INSERM, U674, Fondation Jean Dausset-CEPH, IFR105, Paris F-75010, France; ${ }^{2}$ Université Paris Diderot-Paris 7, Paris F-75013, France; ${ }^{3}$ AP-HP, GHU Est, Hôpital Tenon, Laboratoire d'Histologie et de Biologie Tumorale, Paris F-75020, France; ${ }^{4}$ Université Pierre et Marie Curie-Paris 6, Paris, F-75012, France; ${ }^{5}$ INSERM, U841, IMRB, Créteil F-94000, France; ${ }^{6}$ Faculté de Médecine, Université Paris 12 Val de Marne, IFR10, Créteil F-94000, France; ${ }^{7}$ Université Paris Descartes, Paris F-75006, France and ${ }^{8}$ INSERM, ERI 3, CHU Caen, Caen F-14000, France

${ }^{*}$ Corresponding author: M-C Jaurand, INSERM, U674, Fondation Jean Dausset-CEPH, 27, rue Juliette Dodu, Paris F-75010, France. Tel: + 33153725188 ;

Fax: + 331537251 92; E-mail: jaurand@ cephb.fr

${ }^{9}$ Current address: Institut Curie/CNRS, UMR 7147, F-75005, France

Keywords: mesothelioma; anoikis; SAPK/JNK; Bim; cell junction; $\mathrm{G}_{0}$

Abbreviations: EDTA, ethylenediaminetetraacetic acid; ERK, extracellular signal-regulated kinase; MPM, malignant pleural mesothelioma; NA, non-adherent; PI, propidium iodide; SAPK/JNK, Stress-activated protein kinase/c-Jun NH2-terminal kinase; siRNA, small-interfering RNA; TUNEL, TdT (terminal deoxynucleodityl Transferase)-mediated dUTP-biotin nick end labeling

Received 08.7.08; revised 15.1.09; accepted 24.2.09; Edited by M Piacentini; published online 03.4 .09 
phospho-ERK has been found to be increased in MPM when compared with normal lung tissue. ${ }^{21}$ Inhibition of ERK phosphorylation could suppress prometastatic phenotypes and induce apoptosis in MPM. ${ }^{22,23}$ Alternatively, MPM apoptosis can be induced independently of direct interaction with the above-mentioned pathways. In terms of response to drugs, it has been reported that SAPK/JNK inhibition could reverse the apoptotic effect of TRAIL + etoposide treatment. $^{24}$

The aim of our research was to gain insight into the mechanisms underlying mesothelioma cell survival in nonadherent (NA) conditions. We report that MPM cells placed in NA conditions resist anoikis as well-organized aggregates, according to an atypical process whereby the signaling pathways implicating Akt and ERK are downregulated. With the use of chemical agents and an RNA interference strategy, we identified the signaling pathway and apoptotic proteins involved in this process. These results highlight the role of cell aggregation in MPM cell survival and the anoikis resistance of MPM cells.

\section{Results}

MPM cells are able to grow under NA conditions as wellorganized aggregates. We first determined whether MPM and MeT-5A cells were able to grow under NA conditions. When cultured on a polyHEMA-coated surface, MPM cells form pluricellular aggregates. To determine whether MPM cells aggregates retain the morphological features observed in this disease, we performed transmission electron microscopy (TEM) analysis of three MPM cell lines cultured for 7 days (Figure 1). In the Coro and Hib cell lines, NA aggregates showed well-preserved epithelial organization, with cell polarity - a basal part at the center of the aggregate and an apical part with microvilli at the aggregate periphery (Figure 1a-d). Cells exhibited intercellular junctional complexes composed of desmosomes and adherens junctions (Figure $1 \mathrm{~b}-\mathrm{e}$ ). In Coro, we also observed the presence of perinuclear intermediate filaments and a basal lamina at the center of the aggregate (Figure $1 b$ and $c$ ). Fer cells showed a more stochastic arrangement with a lack of cohesion between cells in some areas (Figure 1f); intercellular junctions were scarce and microvilli were found not only at the periphery of the aggregates but also inside, in the intercellular space (Figure 1g). For the purposes of comparison, no intercellular junctional complexes or cell polarity could be seen in MeT-5A.

The time-dependent evolution of the aggregate size was measured after 1 and 7 days in culture in two MPM cell lines, Hib and Fer, and in MeT-5A cells (Figure 2a). In MPM cell lines, a significant increase in the aggregate size was observed. After 1 day, the mean size was $19 \times 10^{3}$ and $8 \times 10^{3} \mu \mathrm{m}^{2}$ in Hib and Fer, respectively, and reached $55 \times 10^{3}(P<0.001)$ and $14 \times 10^{3} \mu \mathrm{m}^{2}(P<0.01)$ after 7 days. By contrast, the aggregate size of MeT-5A cells did not significantly increase, with a mean size of $6 \times 10^{3}$ at day 1 and $8 \times 10^{3} \mu \mathrm{m}^{2}$ at day 7 .

Proliferation rates were determined to establish to what extent cells remained able to proliferate under NA conditions. Proliferation rates of $2.2 \pm 0.4,1.4 \pm 0.3$ and $1.1 \pm 0.3$ were found in Hib, Fer and MeT-5A, respectively (Figure 2b). By
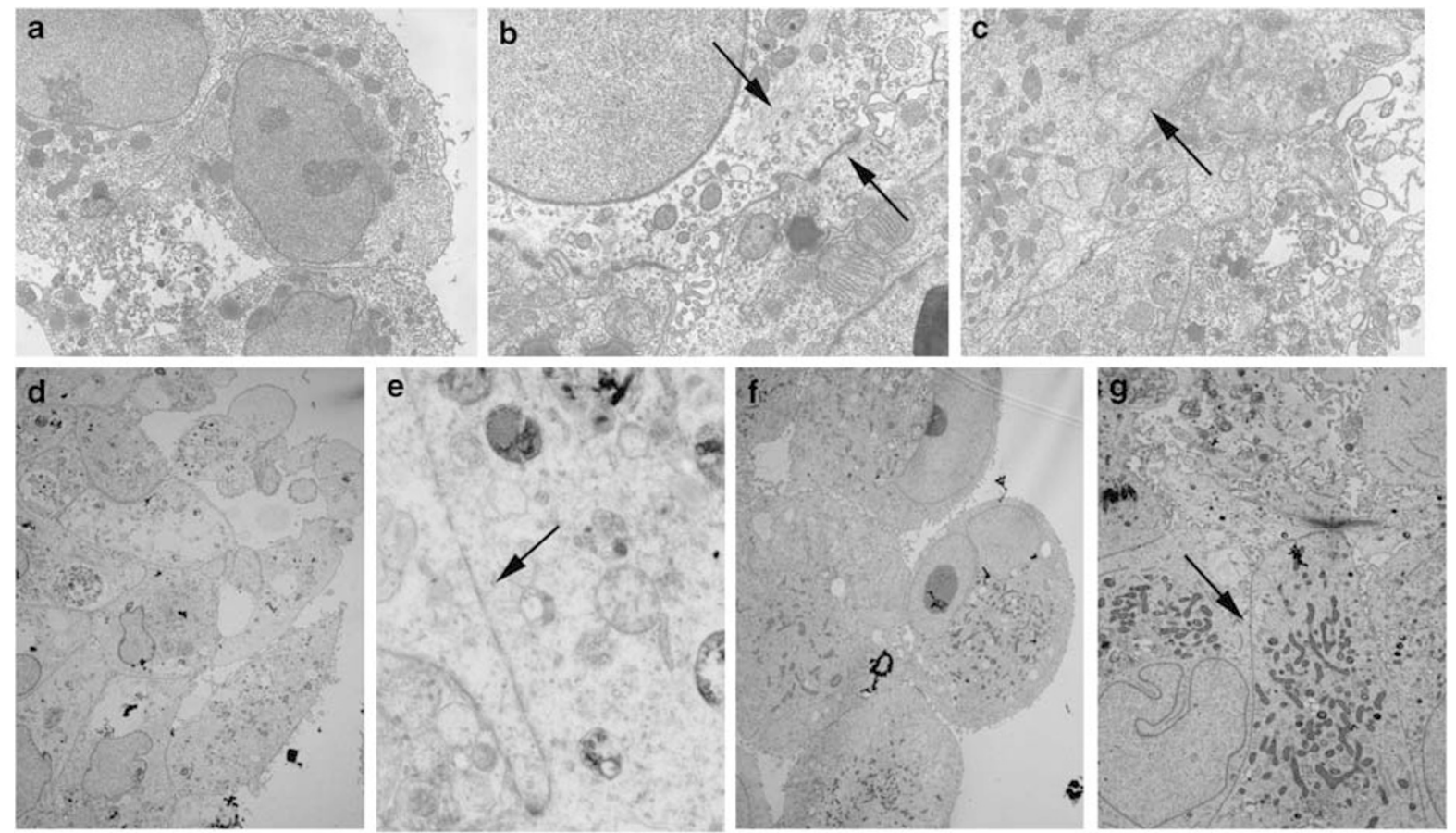

Figure 1 TEM of MPM cell aggregates. Coro (a-c), Hib (d and $\mathbf{e}$ ) and Fer ( $\mathbf{f}$ and $\mathbf{g})$ MPM cells were cultured under non-adherent (NA) conditions for 7 days and then observed by TEM as described in Materials and Methods; (a) $\times 4000$. (b) $\times 10000$ - upper arrow points to intermediate filaments and bottom arrow points to desmosomes. (c) $\times 6000$ - arrow points to basal lamina. (d) $\times 2500$. (e) $\times 5000$ - arrow points to adherens junctions. (f) $\times 2500$. (g) $\times 6000$ - arrow points to adherens junctions 

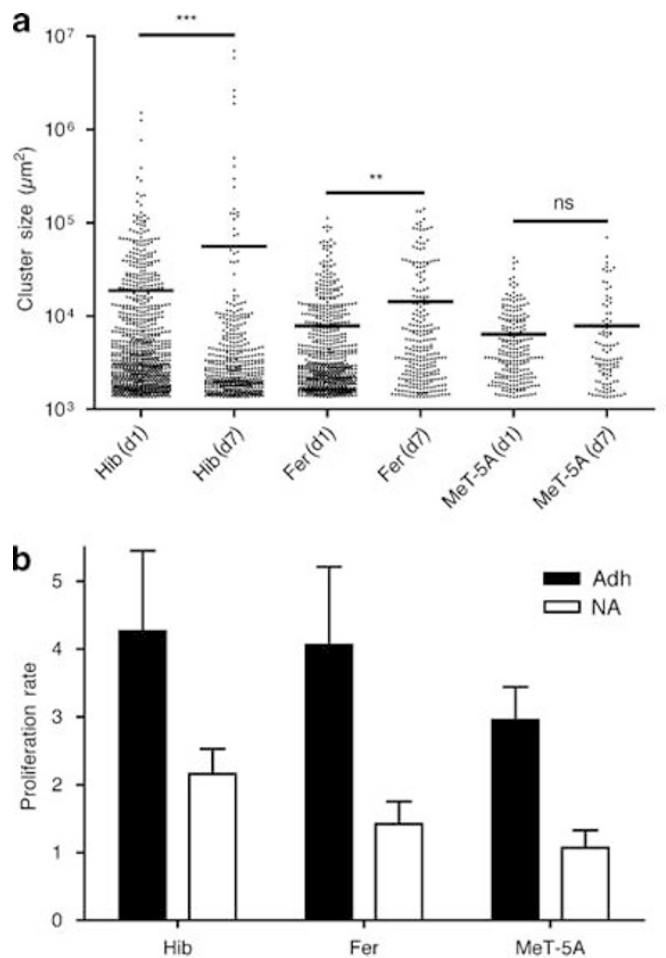
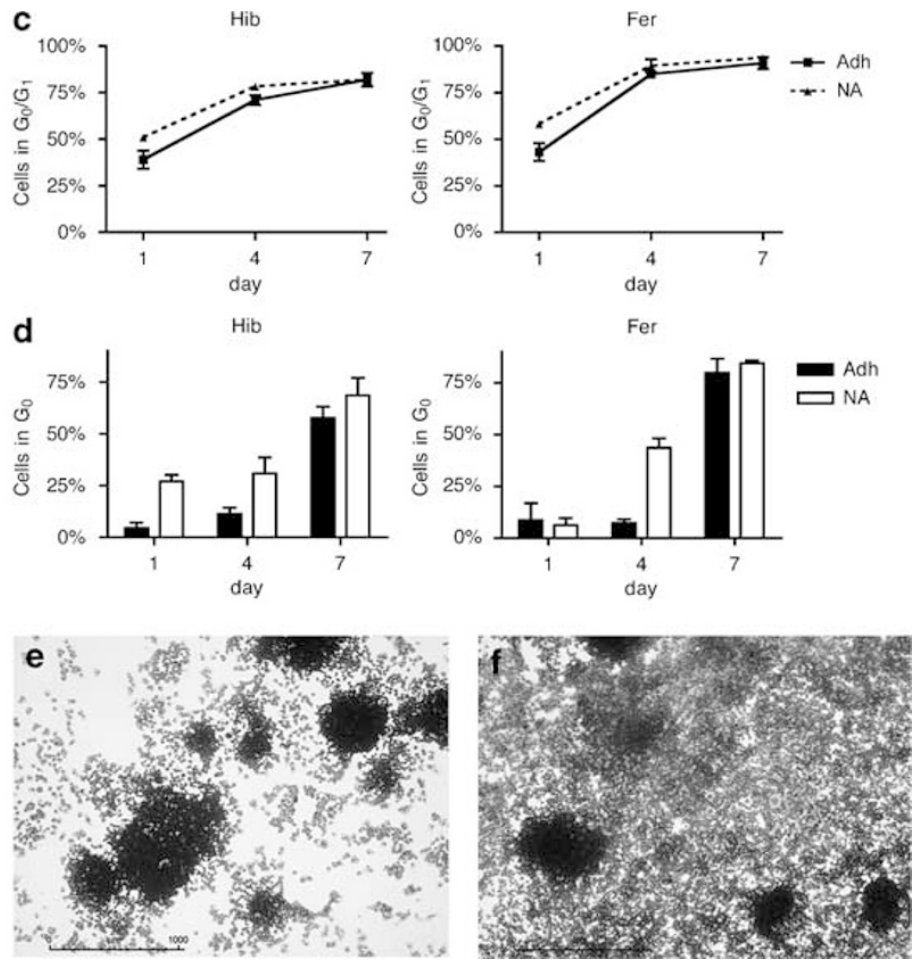

Figure 2 MPM cells proliferate as pluricellular aggregates, which show progressive growth arrest and earlier $\mathrm{G}_{0}$ entry when placed under non-adherent (NA) conditions, and the ability to grow when replaced on a substratum. (a) Aggregate size was measured after 1 and 7 days of culture under NA conditions. In the two MPM cell lines, Hib and Fer, aggregate size increased significantly over time, unlike the non-tumoral cell line MeT-5A (Hib: ${ }^{* \star *} P \leqslant 0.001$; Fer: ${ }^{* \star} P \leqslant 0.01$ ). (b) Proliferation rate at day 7 . Cells were cultured under adherent (Adh) and NA conditions for 1 and 7 days as described in Materials and Methods. We defined the proliferation rate as the ratio of the number of cells at day 7 to that at day 1 . For both MPM and MeT-5A cells, culturing cells under NA conditions reduced proliferation. Nevertheless, Hib and Fer cells still proliferate under NA conditions, unlike the MeT-5A cell line; mean \pm S.D. from five independent experiments. (c) Fraction of cells in $G_{0} / G_{1}$ phase. The fraction of cells in $G_{0} / G_{1}$ phase was determined by the IP-labeling index as described in Materials and Methods. No significant difference was observed in the fraction of cells in $G_{0} / G_{1}$ phase between Adh and NA cells. (d) The fraction of cells in $G_{0}$ was determined from Ki67 labeling as described in Materials and Methods. One day after seeding, the fraction of cells in $G_{0}$ was enhanced under NA conditions for the Hib cell line. Four days after seeding, the fraction of cells in $G_{0}$ was enhanced under NA conditions for both cell lines. Seven days after seeding, most cells are in $G_{0}$ under both Adh and NA conditions. Mean \pm S.D. from four independent experiments. (e and $\mathbf{f}$ ) Fer cell line cultured under NA conditions for 7 days, and then subcultured on LabTek chamber slides for $1(\mathbf{e})$ and 7 days $(\mathbf{f})$; magnification: $\times 25$

comparison, Adh cell proliferation rates were found to be $4.3 \pm 1.2,4.1 \pm 1.2$ and $3.0 \pm 0.5$, respectively, showing that loss of anchorage resulted in a significant decrease in proliferation in all cell lines $(P<0.001)$. Nevertheless, although a significant proliferation rate remained in MPM cells under NA conditions between 1 and 7 days (proliferation rate $>1$; Hib: $P<0.001$; Fer: $P<0.01$ ), there was no growth of MeT-5A. We conclude that MPM cells retained growth capability in the absence of anchorage, unlike MeT-5A.

MPM cells prematurely enter in $\mathbf{G}_{0}$ when cultured under NA conditions. To better compare proliferation under the different culture conditions, we evaluated the fraction of cells in the $G_{0} / G_{1}$ phase in Fer and Hib cell lines, under both NA and Adh conditions, after 1, 4 and 7 days of culture. Under both conditions, the fraction of cells in the $G_{0} / G_{1}$ phase increased with time, and there was no significant difference between NA and Adh cells (Figure 2c).

As no difference was observed in the fraction of $G_{0} / G_{1}$ between NA and Adh cells through PI staining, we decided to determine whether MPM cells were in a quiescent $\left(G_{0}\right)$ or in a cycling $\left(\mathrm{G}_{1}\right)$ state. A comparison of data obtained under NA and $A d h$ conditions showed different kinetics of entry in $G_{0}$, with the use of Ki67 labeling. At 1-day post-seeding, the fraction of cells in $\mathrm{G}_{0}$ was higher in NA than in Adh cultures in one cell line (Hib; $27.0 \pm 3.2$ versus $4.5 \pm 2.7 \%$ for $\mathrm{Hib}$, $P<0.001 ; 6.3 \pm 3.5$ versus $8.6 \pm 8.2 \%$ for Fer, NS). After 4 days, the fraction of cells in $\mathrm{G}_{0}$ was higher in NA than in Adh cultures in both cell lines $(30.9 \pm 7.8$ versus $11.3 \pm 3.1 \%$ for Hib, $P<0.001 ; 43.6 \pm 4.6$ versus $7.2 \pm 1.9 \%$ for Fer, $P<0.001)$. After 7 days, most of the cells were negative for Ki67 labeling, and the fraction of cells in $\mathrm{G}_{0}$ was similar under both conditions for the two cell lines (68.6 \pm 8.5 versus $57.5 \pm 5.7 \%$ for $\mathrm{Hib}$, NS; $84.4 \pm 1.5$ versus $79.7 \pm 6.9 \%$ for Fer, NS; Figure 2d). These results show that NA cells enter in $\mathrm{G}_{0}$ faster than Adh cells.

To determine whether $G_{0}$ entry of NA MPM cells was reversible, aggregates obtained after 7 days under NA conditions were seeded in regular Adh conditions. When observed 1 day after reseeding, cell aggregates were found to reattach to the tissue culture plate, and to experience further growth (Figure $2 e$ and f). Similar results were obtained with 1-month old MPM aggregates (see Supplementary Figure 1).

These results suggest that the control processes of cell cycle progression remain effective in these MPM cells. 
MPM cells are resistant to anoikis. To determine whether MPM cells were resistant to anoikis under NA conditions, we measured the time-dependent evolution of DNA fragmentation by flow cytometry. The percentage of TUNEL-positive cells in MPM cells did not exceed $12.4 \pm 3.2 \%$, and this rate was not significantly modified over time (Figure 3a). By contrast, the MeT-5A cells exhibited a significant rise in positive cells (from $6.8 \pm 2.0 \%$ at day 1 to $44.3 \pm 13.3 \%$ at day $7 ; P \leqslant 0.001)$. When we performed TEM sections of MeT-5A cells cultured for 7 days under NA conditions, we observed fragmented apoptotic
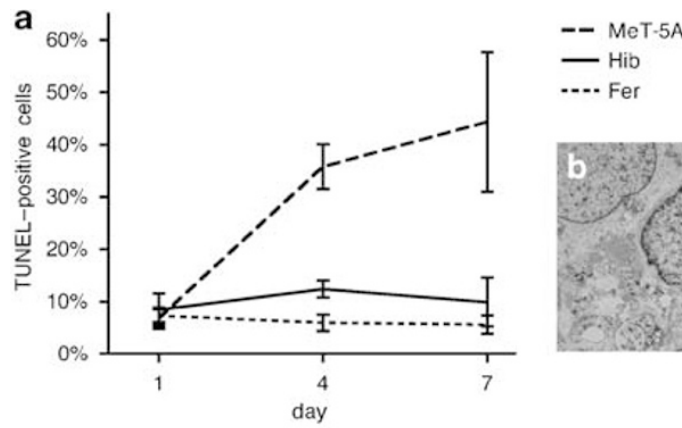

-.... Fer

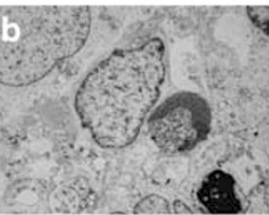

C

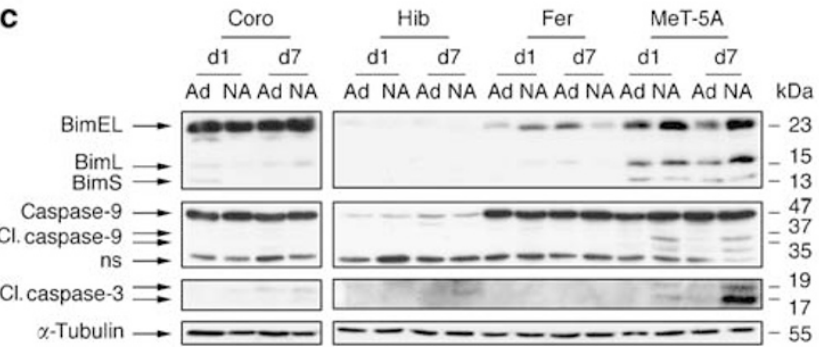

d

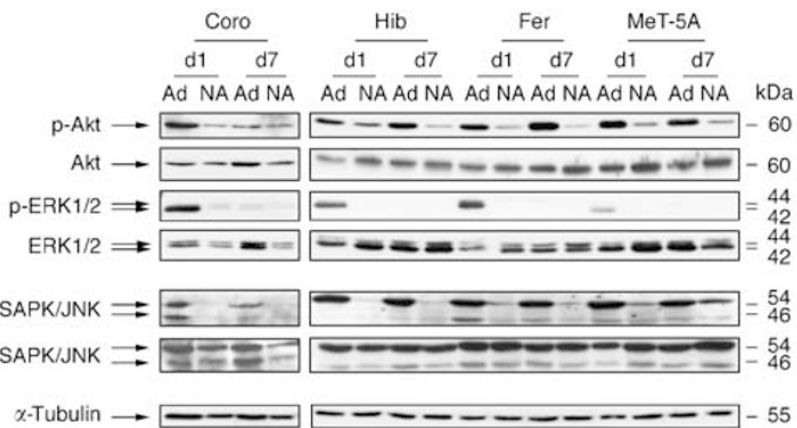

Figure 3 MPM cells are resistant to anoikis despite a downregulation of survival signaling pathways. (a) DNA fragmentation was analyzed by flow cytometry as a function of time under non-adherent (NA) conditions. MeT-5A, but not MPM, cells show a time-dependent increase in the percentage of fragmented DNA. Mean \pm S.D. from three independent experiments. $(b) \times 12000$ : MeT-5A cells were cultured under NA conditions for 7 days and analyzed by TEM as described in Materials and Methods. (c) Cells were cultured under adherent (Ad) and NA conditions for 1 (d1) and 7 days (d7), and immunoblotted for Bim, caspase-9, cleaved caspase-3 (Asp175), and $\alpha$-tubulin was used as a loading control. NA MeT-5A cells exhibited increased expression of Bim, cleaved caspase- 9 and cleaved caspase-3. (d) The same lysates were immunoblotted for phospho-Akt (Ser473), Akt, phospho-ERK (Thr202/Tyr204), ERK, phospho-SAPK/JNK (Thr183/ Tyr185) and SAPK/JNK. All MPM and MeT-5A cells showed a decrease in Akt and ERK phosphorylation when cultured under NA conditions. At day 7, MeT-5A cells specifically expressed phospho-SAPK/JNK, unlike MPM cells nuclei, supporting the finding that the loss of anchorage induces apoptosis in MeT-5A cells (Figure $3 b$ ).

To confirm that cell death observed in the MeT-5A cells was due to apoptosis, we investigated the expression of several proapoptotic proteins, Bim, caspase-9 and caspase-3. Our investigation included the three MPM cell lines (Coro, Hib and Fer) and MeT-5A cells cultured under Adh and NA conditions for 1 and 7 days. As expected, MPM cells did not express the 17 and $19 \mathrm{kDa}$ cleaved forms of caspase-3, in contrast with MeT-5A cells. Moreover, a specific expression of the 35 and $37 \mathrm{kDa}$ cleaved forms of caspase- 9 and an increased Bim expression were observed in NA MeT-5A cells. These results show that in MeT-5A, but not in MPM cells, loss of anchorage induces anoikis. They further suggest the involvement of Bim, caspase- 9 and caspase-3 (Figure 3c).

MPM cells exhibit a massive hypophosphorylation of signaling pathways under NA conditions. The PI3K/Akt pathway has been reported to be the major signaling pathway upregulated in anoikis-resistant cells. To determine whether this pathway is responsible for anoikis resistance in MPM cells, we investigated the expression of the phosphorylated form of the Akt protein (S473) at 1 and 7 days after seeding in MPM and MeT-5A cells, under both NA and Adh conditions. When the protein was cultured under NA conditions, a massive and rapid decrease in the expression of phospho-Akt was observed (Figure 3d). By contrast, MPM and MeT-5A cells expressed phospho-Akt under Adh conditions.

As the activation of the MAP kinases signaling pathway may also account for the resistance to apoptosis, the expression of phospho-ERK1/2 proteins was determined under both NA and Adh conditions. As found in phospho-Akt, MPM and MeT-5A cells exhibited a massive decrease in the expression of phospho-ERK1/2 when cultured under NA conditions (Figure 3d). It must be noted that phospho-ERK1/2 expression is lower in MeT-5A Adh cells when compared with MPM cells, possibly accounting for the observed lower proliferation rate of these cells. However, phospho-ERK1/2 downregulation was different from that of phospho-Akt. Although the level of phospho-Akt expression remained roughly stable between days 1 and 7 in Adh cells, a decrease associated with an increase in cell density was found between days 1 and 7 in Adh MPM and MeT-5A cells.

MeT-5A cells undergo anoikis in an SAPK/JNK-, Bimand caspase-9-dependent pathway. The SAPK/JNK pathway has been reported to be implicated in anoikis. We studied the expression of phospho-SAPK/JNK in MPM and MeT-5A cells. Similarly to Akt and ERK, loss of anchorage induced a massive downregulation of the phosphorylated form of the SAPK/JNK protein in MPM cells. By contrast, MeT-5A still expressed the phosphorylated form of SAPK/ JNK when cultured under NA conditions (Figure $3 c$ ).

To confirm that anoikis was linked to SAPK/JNK phosphorylation in MeT-5A cells, we determined the effect of the SAPK/JNK inhibitor, SP600125, on DNA fragmentation in MeT-5A cells cultured under NA conditions. A dose-dependent decrease of TUNEL-positive cells was found, showing a significant difference with an SP600125 concentration of $3 \mu \mathrm{M}$ 
( $P \leqslant 0.05$; Figure 4a). Accordingly, this decrease was associated with a decrease in the caspase-3 activity (Figure $4 \mathrm{~b}$ ). There was also a dose-dependent decrease in c-Jun phosphorylation, consistent with decreased SAPK/JNK activity (Figure 4c).

We then examined the effect of C-Jun, Bim and caspase-9 knockdown by siRNA on the expression of the 17 and $19 \mathrm{kDa}$ cleaved forms of caspase- 3 in NA Met-5A cells. We observed that inhibition of either c-Jun, Bim or caspase-9 expression reduced the expression of the cleaved forms of caspase-3 (Figure 4d-f). These results confirm the involvement of the SAPK/JNK-C-Jun pathway and support a role for Bim and caspase- 9 in anoikis in MeT-5A cells.

Anisomycin induces apoptosis in NA MPM cells in a c-Jun-, Bim- and caspase-9-dependent pathway. To determine whether the phospho-SAPK/JNK downregulation associated with loss of anchorage is linked to anoikis resistance in MPM cells, we examined the dose-dependent effect of the SAPK/JNK activator, anisomycin, on SAPK/JNK phosphorylation, cleaved-caspase-3 expression and caspase-3 activity. We found that anisomycin induced both expression of phospho-SAPK/JNK and of the cleaved form of the caspase-3, as well as an increase in the activity of caspase-3 (Figure $5 \mathrm{a}$ and b). As significant caspase-3 activity enhancement was found in $1 \mu \mathrm{g} / \mathrm{ml}$ anisomycin, this dose was selected for all subsequent experiments.
Moreover, we found that anisomycin treatment reduced viability of NA MPM cells (data not shown).

We then tested to see whether c-Jun, Bim or caspase-9 suppression by siRNA knockdown would protect cells from SAPK/JNK-linked apoptosis. In all three MPM cell lines, we observed that c-Jun, Bim or caspase-9 knockdown, all reduced caspase- 3 cleavage in anisomycin-treated cells (Figure $5 \mathrm{c}$ and e).

These results support a role for SAPK/JNK activation in the apoptotic process, involving c-Jun, Bim and caspase- 9 cleavage.

Cell aggregation prevents anoikis and SAPK/JNK and Bim activation. To determine the role of aggregate assembly in the resistance of MPM cells to anoikis, MPM cells were cultured under spinning to avoid cell aggregation for 1, 4 and 7 days, and the expression of phospho-SAPK/ JNK, cleaved-caspase-3 and Bim was determined. In the three cell lines, spinning produced a net increase in the expression of these proteins in a time-dependent manner (Figure 6a). Accordingly, a significant decrease in cell viability was observed (Figure 6b). These results support a role for cell-cell contact in anoikis resistance of MPM cells.

Anoikis resistance involves calcium-dependent intercellular junctions in MPM cells. To determine whether calcium-dependent intercellular junctions could be

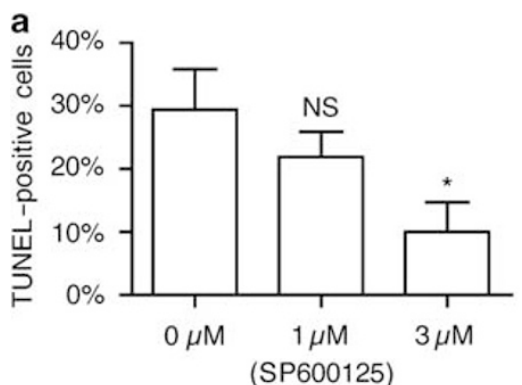

C

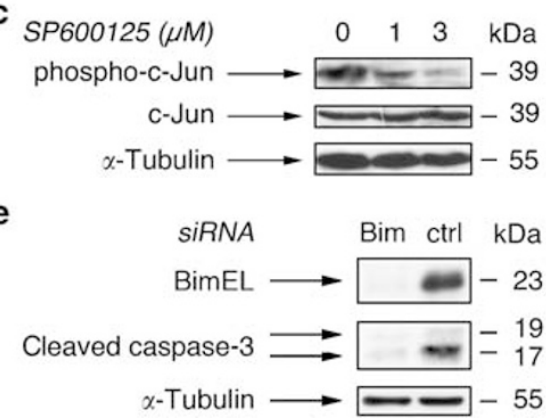

b

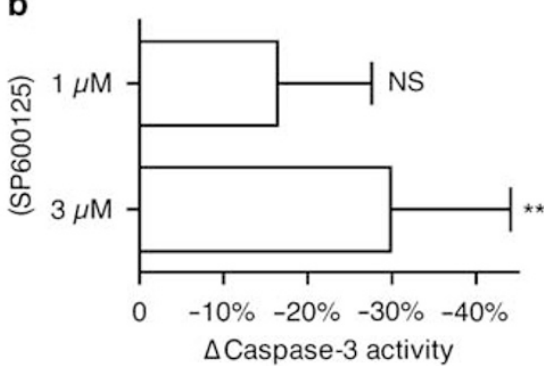

d

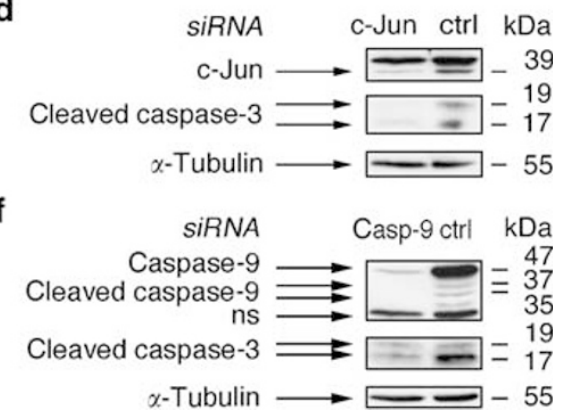

Figure 4 MeT-5A cell line enters anoikis in an SAPK/JNK- and Bim- and caspase-9-dependent pathway. (a) MeT-5A cells were cultured under non-adherent (NA) conditions for 7 days, in the absence or presence of 1 or $3 \mu \mathrm{M} \mathrm{SP600125}$, and analyzed for DNA fragmentation by flow cytometry. At a dose of $3 \mu \mathrm{M}$, SP 600125 significantly decreased the percentage of DNA fragmented cells ( $\left.{ }^{*} P<0.05\right)$; mean $\pm S D$ from three independent experiments. (b) MeT-5A cells were treated as in (a) and analyzed for caspase-3 activity by fluorometry. The $\mathrm{X}$ axis indicates the difference $(\Delta)$ in caspase- 3 activity, defined as the difference between the activity of caspase- 3 cells in treated and untreated as a percentage of the caspase- 3 activity in untreated cells. A significant decrease in the activity of caspase-3 was found in $3 \mu \mathrm{M}$ SP600125 $\left(^{* *} P<0.01\right)$. Mean \pm S.D. from five independent experiments. (c) MeT-5A cells were treated as in (a) and (b) and immunoblotted for phosho-c-Jun (Ser63) and c-Jun, and $\alpha$-tubulin expression was used as a loading control. SP600125 abolished c-Jun phosphorylation in a dose-dependent manner. (d-f) MeT-5A cells were cultured under NA conditions for 7 days in the presence of specific or control (ctrl) siRNAs, and immunoblotted for c-Jun, Bim, caspase-9, cleaved caspase-3 (Asp175) and $\alpha$-tubulin. Expression of $\alpha$-tubulin was used as a loading control. With c-Jun siRNA, c-Jun downregulation is associated with caspase-3 cleavage (d). Bim and caspase-9 siRNAs suppress Bim and caspase-9 expressions, respectively, and reduce cleaved caspase-3 expression (e and f) 


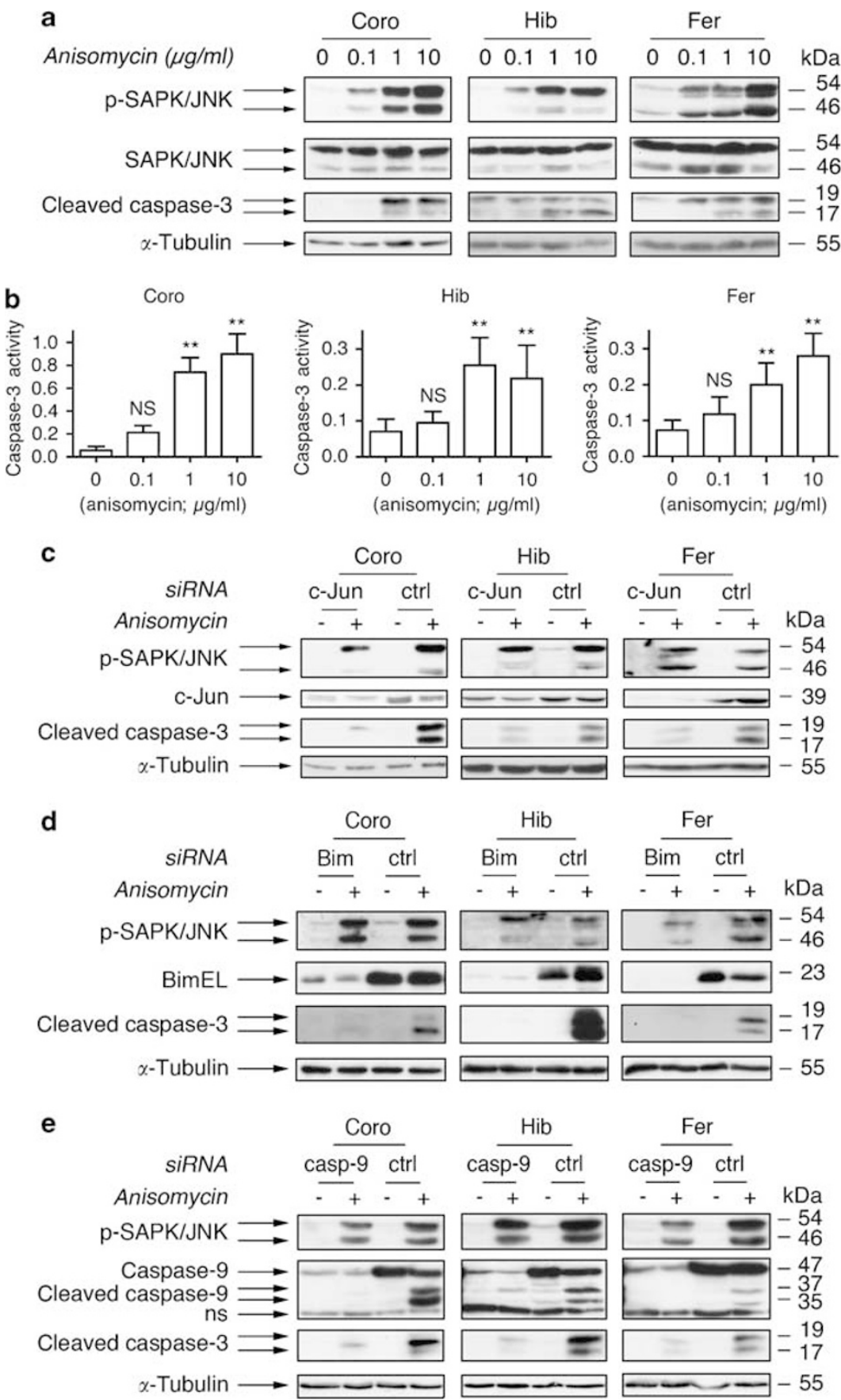

Figure 5 Anisomycin induces apoptosis in MPM cells in a Bim- and caspase-9-dependent pathway. (a) MPM cells were cultured under non-adherent (NA) conditions for 7 days and treated with $0.1,1$ or $10 \mu \mathrm{g} / \mathrm{ml}$ anisomycin for $4 \mathrm{~h}$, and immunoblotted for SAPK/JNK, phospho-SAPK/JNK (Thr183/Tyr185), caspase-9, cleaved capsase-3 (Asp175) and $\alpha$-tubulin as a loading control. In all cell lines, anisomycin induced SAPK/JNK phosphorylation and caspase-3 cleavage. (b) MPM cells were treated as in (a) and analyzed for caspase-3 activity by fluorometry, resulting in an increase in the activity of caspase-3. Enhancement from $1 \mu \mathrm{g} / \mathrm{ml}$ was significant ${ }^{* *} P<0.01$ ); mean \pm S.D. from four independent experiments. (c-e) MPM cells were cultured under NA conditions for 7 days in the presence of specific or control (ctrl) siRNAs, treated ( + ) or not $(-)$ with $1 \mu \mathrm{g} / \mathrm{ml}$ anisomycin for $4 \mathrm{~h}$, and immunoblotted for phospho-SAPK/JNK (Thr183/Tyr185), c-Jun, Bim, caspase-9, cleaved caspase-3 (Asp175) and $\alpha$-tubulin as a loading control. In all cell lines, c-Jun downregulation prevented anisomycin-induced caspase-3 cleavage (c), Bim downregulation prevented anisomycin-induced caspase-3 cleavage (d) and caspase-9 downregulation prevented anisomycin-induced caspase-3 cleavage (e)

involved in aggregate formation and anoikis resistance of MPM cells, we investigated the role of EDTA on the size of aggregates and on caspase- 3 activity. After 7 days of culture, EDTA prevents the formation of larger pluricellular aggregates in Coro and Fer cell lines, and induces a significant decrease in the size of aggregates in Hib cell lines (Figure 7a). Moreover, EDTA induces a significant increase in the activity of caspase- 3 in the three cell lines 
a

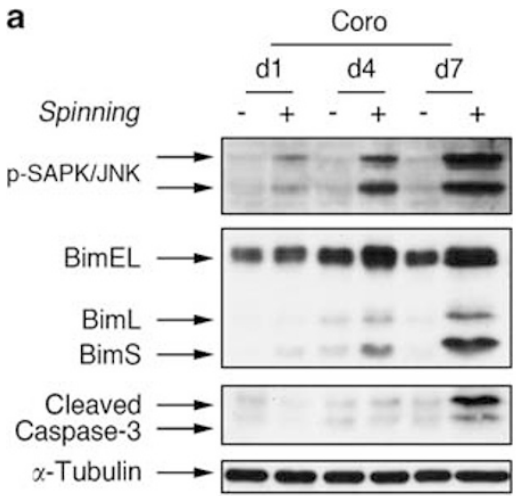

b

Coro

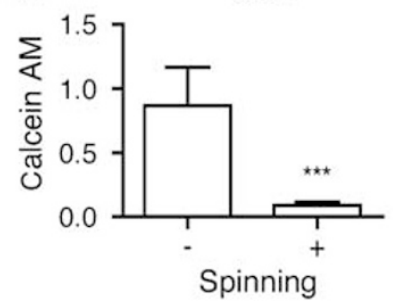

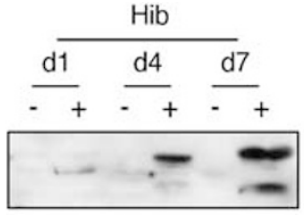
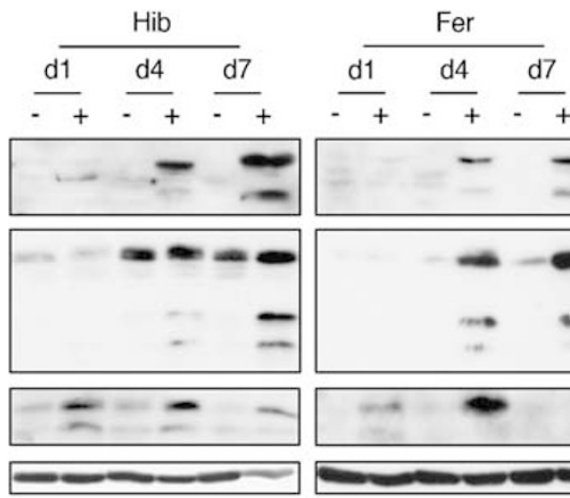

Hib
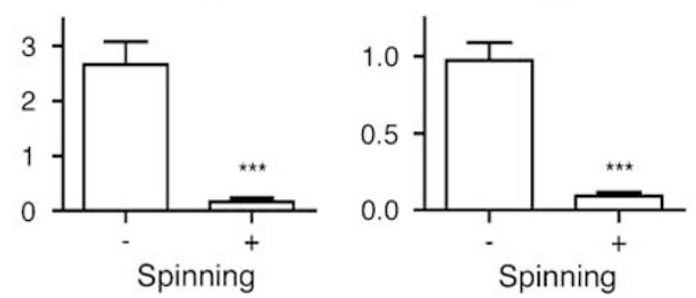

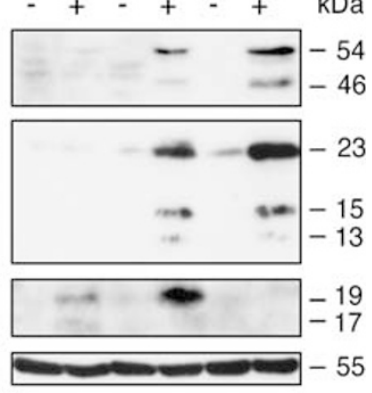

Fer

Figure 6 Aggregation prevents MPM cells from SAPK/JNK and Bim linked anoikis. (a) MPM cells were cultured or under spinning $(+)$ or not $(-)$ for 1,4 and 7 days, and immunoblotted for phospho-SAPK/JNK (Thr183/Tyr185), Bim, cleaved capsase-3 (Asp175) and $\alpha$-tubulin as a loading control. In all cell lines, spinning induced SAPK/JNK phosphorylation, Bim expression and caspase-3 cleavage. (b) MPM cells were cultured or under spinning $(+)$ or not $(-)$ for 7 days, stained with $2 \mu \mathrm{M}$ calcein AM and analyzed by fluorometry. In all cell lines, spinning significantly reduced cell viability $\left.{ }^{\star \star \star} P \leqslant 0.001\right)$. Fluorescence levels were measured in triplicate; mean \pm S.D. from three independent experiments

tested (Figure 7b). These results support a role for calciumdependent intercellular junctions in the anoikis resistance of MPM cells as pluricellular aggregates.

\section{Discussion}

Cell aggregates in serous fluid may be responsible for tumor diffusion in the pleural cavity. Our study investigated this major characteristic of mesothelioma, which to date has been the focus of very little research. When cultured under NA conditions, MPM cells form aggregates, which exhibit striking morphological and cytological similarities with pathological criteria. In serous effusions, MPM cell aggregates show a diversity of structures; some display a true papillary structure, whereas others exhibit structures of pseudoacinar formation or randomly coiled cords of cells. ${ }^{4}$ In our model of pluricellular aggregates, two MPM cell lines displayed micropapillary-like structures, whereas the other displayed less typical structures. Moreover, MPM cell aggregates presented some features described in cells in epithelial effusion, showing Adh junctions, basal lamina, microvilli and intermediate filaments adjacent to the nuclear envelope, which are diagnostic criteria for mesothelioma. ${ }^{3,25}$

In this study, we showed that the size of the MPM cell aggregates increased over time as a result of the MPM cells' ability to grow in the absence of anchorage to a substrate. On the basis of Ki67 immunochemical staining experiments, Kim et $a^{2} .^{26}$ reported that cell proliferation was maintained in mesothelioma tumor fragments cultured under NA conditions and that the rate of proliferation did not differ from the original tumor. Using a different culture mode, our data confirm that
MPM cell aggregates retain growth capability under NA conditions. We also found that this property differs from non-tumoral MeT-5A cells, which do not grow. MPM cell growth did not persist in cell aggregates, and cells enter in $\mathrm{G}_{0}$; but this growth arrest was reversible, as MPM aggregates attach and proliferate when plated under regular culture conditions. Similar observations were made with hepatoma cells. ${ }^{27}$ These data suggest that a growth control process can remain effective in NA tumor cells. These characteristics could be advantageous for the diffusion and colonization of MPM cells in the pleural cavity.

Signaling pathways play a critical role in cell cycle progression; their rapid inactivation after loss of anchorage likely accounts for the reduced proliferation and entry in $G_{0}$ observed in NA MPM cells. In Adh MPM cells, ERK inactivation may be due to cell confluence and contact inhibition, causing cells to enter in $G_{0}$ at a later point in time. In numerous cell and tissue types, the efficiency of growthfactor receptor activation is regulated by anchorage. ${ }^{28} \mathrm{We}$ found in separate experiments that the activation of signaling pathways in response to serum stimulation was substantially diminished in serum-starved NA MPM and MeT-5A cells when compared with serum-starved Adh cells. These findings suggest that the downregulation of signaling pathways induced by loss of matricial anchorage may be due to disruption of integrin and growth-factor receptor signaling cross-talk (see Supplementary Figure 2). Indeed, loss of anchorage accelerates the cell cycle exit. Subsequently, MPM cells resist anoikis as quiescent, well-organized aggregates. Activation of signaling pathways is considered to be the cause of anoikis resistance. Nevertheless, 

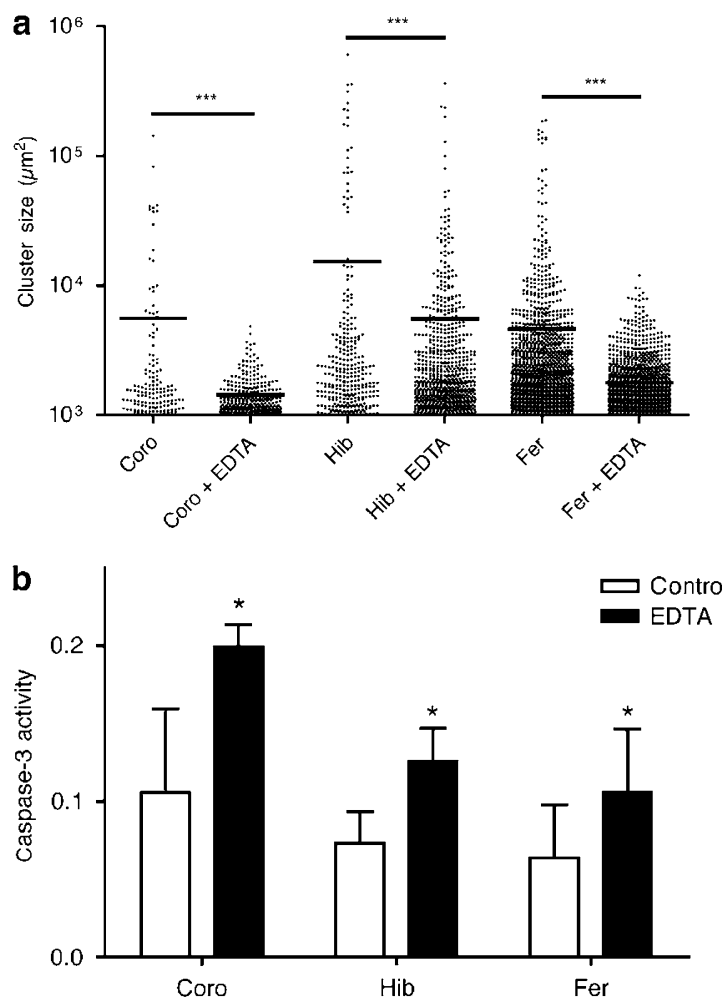

Figure 7 Calcium-dependent cell-cell adhesion is involved in aggregation and anoikis resistance of MPM cells. (a) MPM cells were cultured under non-adherent (NA) conditions for 7 days in the presence or absence of $0.4 \mathrm{mM}$ EDTA, and the size of the aggregates was measured. In all cell lines, EDTA significantly decreased the size of the aggregates $\left({ }^{* \star *} P \leqslant 0.001\right)$. (b) MPM cells were treated as in (a) and analyzed for caspase-3 activity by fluorometry. In all cell lines, EDTA significantly increased caspase-3 activity $\left({ }^{*} P \leqslant 0.05\right)$; mean \pm S.D. from at least three independent experiments

phospho-Akt has previously been described as being downregulated in MPM cells cultured under NA conditions without the occurrence of apoptosis. ${ }^{29,30}$ In this study, we found that the ERK pathway was also rapidly downregulated in NA MPM cells. By contrast, downregulation of phospho-Akt and phospho-ERK in non-tumoral MeT-5A was associated with anoikis.

The mechanism of anoikis resistance in MPM aggregates shares similarities with apoptosis resistance, such as the activation of apoptotic proteins and the inactivation of antiapoptotic proteins. $^{5}$ Some experimental evidence supports a proapoptotic role of SAPK/JNK in anoikis. ${ }^{12,14}$ We observed that phospho-SAPK/JNK was downregulated in NA MPM cells, whereas this protein was activated in MeT-5A cells, suggesting that the loss of anchorage-dependent apoptosis was related to the activation of this pathway. Several studies report a specific role of Bim in anoikis. ${ }^{7,31} \mathrm{Bim}$ is apparently sequestered by microtubule-associated dynein light chain-1 and could serve as a sensor for microtubule cytoskeleton integrity. ${ }^{32,33}$ SAPK/JNK can phosphorylate Bim and then break its association with the cytoskeleton. ${ }^{34} \mathrm{We}$ found here that MeT-5A cells entered anoikis through Bim and caspase- 9 activation, and that inhibition of the SAPK/JNK pathway suppressed cell death. Conversely, by activating SAPK/JNK with anisomycin in NA MPM cells, we found that
MPM cells could enter c-Jun-, Bim- and caspase-9-dependent apoptosis. The role of $\mathrm{Bim}$ in response to anisomycin treatment in mesothelioma has already been described by Abayasiriwardana et al., ${ }^{35}$ who reported that low doses of anisomycin combined with TRAIL induced apoptosis through Bim stabilization in Adh MPM cells. They also found that anisomycin did not affect the expression level of the caspase8 interactor, FLIP, suggesting that anisomycin sensitized MPM cells at the level of the mitochondria. Here, we show that apoptosis may be triggered through caspase- 9 cleavage in NA MPM cells without the addition of TRAIL.

Cell aggregation protects MPM cells against anoikis. A process in which cell survival requires cell-cell interactions has been advanced in studies on squamous carcinoma cells and termed as 'synoikis'. ${ }^{36}$ We observed that MPM cells in aggregates are associated, through desmosomes and adherens junctions in particular, and found that interaction with these calcium-dependent intercellular junctions reduced pluricellular aggregate formation and induced anoikis. These results are consistent with findings of a coexpression of the $\mathrm{E}-, \mathrm{N}$ - and P-cadherins in MPM effusions. ${ }^{37}$ Some MPM cell aggregates display basal lamina, which led us to suppose that elements of the cell-extracellular matrix interactions could play a role in the anoikis resistance of MPM cells. Integrin receptors may be of particular interest; they have been implicated in the anoikis process for other cell types. In particular, blocking 31 -integrin signaling induces Bim upregulation and anoikis in NA cultured MCF10A cells. ${ }^{38}$ Mesothelin, a membrane glycoprotein, which has been described as being overexpressed in mesothelioma and playing a role in cellular adhesion, can prevent anoikis when overexpressed in human breast cancer cells by suppressing Bim induction. ${ }^{39,40}$ In our studies, mesothelin suppression by siRNA did not affect Bim or caspases expression, nor did it affect cell aggregation (data not shown).

Bim belongs to the 'BH3-only activator' subfamily of $\mathrm{Bcl}-2$ proapoptotic proteins. ${ }^{41}$ Our study shows the key role of Bim in the apoptosis process of MPM cells. This is consistent with the findings of other researchers, namely that the antiapoptotic Bcl-2 protein, $\mathrm{Bcl}-\mathrm{x}_{\mathrm{L}}$, capable of sequestering Bim, is commonly expressed in mesothelioma. ${ }^{16}$ The adjunction of $\mathrm{BH} 3$ mimetics behaving, like Bim, as targets of Bcl- $\mathrm{x}_{\mathrm{L}}$, might offer a new approach to improve the effects of conventional chemotherapy agents used for the treatment of mesothelioma, and could counteract mesothelioma resistance to chemotherapy. Recent studies point to the potential of ' $\mathrm{BH} 3$ mimetics' as anticancer drugs or enhancers of conventional chemotherapy for various types of cancer. ${ }^{41}$

In summary, we have shown that MPM cells resist anoikis as quiescent and well-organized pluricellular aggregates with particular relevance for the disease MPM, and we have suggested mechanisms to counteract this resistance. Further studies are needed to identify the main factors implicated in MPM cell aggregation, and to elucidate the upstream mechanisms that prevent SAPK/JNK activation, with particular relevance for potential therapies to treat the disease MPM.

\section{Materials and Methods}

Cell lines. Three human MPM cell lines (Coro, Hib and Fer) were developed in the laboratory. ${ }^{42}$ They were used between passages 7 and 20 . All cell lines have 
shown tumorigenicity after injection in nude mice. MeT-5A cell line (CRL-9444) was obtained from ATCC (Manassas, VA, USA). The MeT-5A cells were derived from mesothelial cells isolated from pleural fluids obtained from non-cancerous individuals, and transfected with the PRSV-T plasmid. They were used as normal, non-tumoral epithelial mesothelial cells.

Cell culture and materials. Human mesothelioma cells and MeT-5A were routinely maintained in RPMI 1640 + GlutaMAX medium, buffered with $25 \mathrm{mM}$ HEPES (Invitrogen, Cergy Pontoise, France) supplemented with 10\% fetal bovine serum (Invitrogen) and penicillin/streptomycin (Invitrogen) at $37^{\circ} \mathrm{C}$ in a humidified atmosphere containing $5 \% \mathrm{CO}_{2}$.

Culturing under NA conditions was performed by seeding $10^{5} \mathrm{cell} / \mathrm{s} / \mathrm{ml}$ on polyHEMA-coated 24-, 12- or 6-well tissue culture plates (Falcon, Dutscher, Brumath, France)..$^{30}$ PolyHEMA, purchased from Sigma (Saint-Quentin Fallavier, France), was first dissolved in absolute ethanol at a concentration of $10 \mathrm{mg} / \mathrm{ml}$, and used at a final concentration of $0.5 \mathrm{mg} / \mathrm{cm}^{2}$. Plates were dried overnight at $37^{\circ} \mathrm{C}$ and washed with PBS (Invitrogen) before cell seeding.

Culturing under spinning was performed by seeding $10^{5} \mathrm{cell} / \mathrm{s} / \mathrm{ml}$ on a Wheaton Celstir spinner flask (Dutscher).

For reattachment experiments, cells were first cultured under NA conditions for 7 days, and subcultured on LabTek chamber slides for 1 and 7 days.

EDTA (Bioprobe Systems, Montreuil, France) was used at a concentration of $0.4 \mathrm{mM}$. Anisomycin (A9789) obtained from Sigma and SP600125 from Calbiochem (VWR, Val de Fontenay, France)

Antibodies. Immunoblotting was performed with one of the following primary antibodies: anti-Phospho-Akt (Ser473), anti-Bim, anticleaved caspase-3 (Asp175), anticaspase-9 (human specific), anti-p44/42 MAP kinase, anti-Phospho-p44/42 MAP kinase (Thr202/Tyr204), and anti-SAPK/JNK (56G8) all from Cell Signaling (Ozyme, Saint Quentin-en-Yvelines, France), anti-Phospho-SAPK/JNK (Thr183/ Tyr185), anti- $\alpha$-tubulin (BD Biosciences, Le Pont de Claix, France), anti-Akt1/2 $(\mathrm{H}-136)$, anti-c-Jun $(\mathrm{N})$ from Santa Cruz (Tebu, Le Perray En Yvelines, France), and anti-Phospho-c-Jun (Ser63; thanks to Dominique Lallemand).

Secondary antibodies were either rabbit or mouse horseradish peroxidase-linked antibodies (Santa Cruz).

Ki67 labeling was performed with anti-Ki67-FITC (clone MIB-1; DakoCytomation, Trappes, France).

Cell proliferation analysis. Cells were seeded on either poly-HEMA-coated or non-coated 12-well tissue culture plates at a concentration of $10^{5}$ cells $/ \mathrm{ml}$. Adherent cells and cell aggregates were dissociated by trypsin treatment 1 and 7 days post-seeding, and the cell count was determined using the Coulter Z2 cell counter (Beckman Coulter, Villepinte, France). The proliferation rate was determined using the ratio of the number of cells counted at day 7 to the number at day 1 post-seeding. Results were obtained from five independent experiments.

Light microscopy and aggregate size measurement. Cells were cultured under NA conditions for 1, 4 and 7 days, cytocentrifuged on glass slides, and stained using May Grünwald Giemsa (MGG; Biolyon, Dardilly, France). Ten slides were made for each incubation time. Images from five different areas on each slide, at $\times 25$ and $\times 100$ magnifications, were systematically captured with a Zeiss microscope and a tri-CCD camera (JVC, USA) using Archimed software (ALPHESIS, France). Size was determined by image analysis using ImageJ $1.38 \mathrm{q}$ software.

Transmission electron Microscopy (TEM). Cells were cultured under NA conditions for 7 days, then fixed in $2.5 \%$ glutaraldehyde in cacodylate buffer (Euromedex, Souffelweyersheim, France) and posfixed with 1\% osmium tetroxyde (Euromedex). Cells were then dehydrated using a graded series of ethanol and propylene oxide, and embedded in epon (Euromedex) as described above. Ultrathin sections were contrasted using uranyl acetate and lead citrate (Euromedex).

Cell cycle analysis and Ki67 labeling. Cells were cultured under Adh and NA conditions for 1, 4 and 7 days. For Ki67 staining, nuclei were extracted with a polyamine buffer and fixed with PFA (0.5\% in PBS) (Sigma). Nuclei were then posfixed in $70 \%$ ethanol and nuclear membranes were permeabilized with $2.5 \%$ Triton X100-PBS. Nuclei were double labeled with a Ki67-FITC antibody and propidium iodide (Coulter DNA prep reagent kit, Beckmann Coulter, Villepinte, France), and then analyzed by flow cytometry (Epics Elite, Beckman Coulter). Cell cycle analyses were performed using Wincycle software (Phoenix Flow Systems, San Diego, CA, USA). Results were obtained from four independent experiments.

DNA fragmentation assay. Cells were cultured under Adh and NA conditions for 1, 4 and 7 days, and assayed for DNA fragmentation using the FlowTACS Apoptosis Detection Kit, according to the manufacturer's protocol (R\&D Systems, Lille, France). Results were obtained from at least three independent experiments.

Caspase-3 activity assay. Cells were cultured under NA conditions for 7 days and assayed for caspase- 3 activity using the caspase- 3 fluorometric protease assay (Caspase-3 Apoptosis Detection Kit from Santa Cruz) according to the manufacturer's protocol (sc-4263 AK, Tébu). Results were obtained from at least four independent experiments.

Cell viability: calcein AM assay. Calcein AM (04558; Sigma) is a fluorescent marker of cell viability that labels viable cells. Cells were seeded under NA conditions or under spinning, cultured for 7 days, and incubated in the presence of $2 \mu \mathrm{M}$ calcein AM at $37^{\circ} \mathrm{C}$ for $1 \mathrm{~h}$. Fluorometric detection was performed using the fluorescence measurement system Cytofluor 2350 (Millipore; Saint-Quentin-enYvelines; France).

Fluorescence was normalized to the number of cells using bisbenzimide $\mathrm{H} 33342$ staining (14533; Fluka). A negative control was performed by incubating cells 10 min with $0.1 \%$ saponin (Sigma) before calcein AM incubation. Results were obtained from three independent experiments

Immunoblotting. Total proteins were extracted from mesothelial cells using the RIPA buffer (Euromedex) supplemented with protease inhibitor mixture (Complete, Roche, Meylan, France), and lysates were incubated for $1 \mathrm{~h}$ on ice and cleared by centrifugation $\left(20 \mathrm{~min}\right.$ at $4{ }^{\circ} \mathrm{C}$ and $16000 \mathrm{~g}$ ). Protein concentration of the supernatants was assessed using Lowry dosing (Biorad). Proteins were denaturated by boiling for $5 \mathrm{~min}$ in Laemmli buffer and analyzed on a reducing sodium dodecylsulfate-polyacrylamide gel. Proteins were blotted to PVDF membrane (Millipore) by electrotransfer. Membranes were blocked for $1 \mathrm{~h}$ at room temperature, with $5 \%$ non-fat dry milk in PBS $1 \times$ and then incubated overnight at $4{ }^{\circ} \mathrm{C}$ with primary antibodies. After washing three times with PBS $1 \times$ supplemented with $0.1 \%$ Tween 20 , membranes were incubated with secondary antibodies for $1 \mathrm{~h}$ at room temperature. After washing three times in PBS $1 \times$ supplemented with $0.1 \%$ Tween 20 , detection was performed by using chemiluminescence with $\mathrm{ECL}$ or $\mathrm{ECL}$ + reagent (GE Healthcare, Aulnay sous Bois, France).

siRNA-targeted knockdown. RNA interference was used to knockdown c-Jun, Bim or caspase-9 protein expression in MPM and MeT-5A cells. The c-Junpredesigned siRNA was obtained from Ambion (s7658; Courtaboeuf, France). The Bim- and caspase-9-predesigned siRNA were obtained from Santa Cruz (sc-29802 and sc-29931 respectively; Tebu). As a control, cells were transfected with Silencer Negative Control \#1 siRNA (Ambion). Knockdown was performed by reverse transfection of siRNA into cells using Lipofectamine RNAiMAX reagent (Invitrogen) according to the manufacturer's instructions. Efficient transfection was verified by using the control siRNA (fluorescein conjugate)-D (sc-44241; Tebu), and successful targeted knockdown was verified by immunoblot after transient cell transfection with siRNA.

Briefly, $10^{5} \mathrm{cells} / \mathrm{ml}$ were seeded on poly-HEMA-coated dishes and transiently transfected with $50 \mathrm{nM}$ siRNA, using $2.5 \mu \mathrm{l} / \mathrm{ml}$ of Lipofectamine RNAiMAX. After 7 days of incubation, transfected cells were analyzed for protein expression using western blot.

Statistical analysis. Data are expressed as mean \pm S.D. Statistical analyses were carried out using Prism 4.0 Software. The statistical significance between groups in normally distributed continuous variables was determined using Student's $t$-test or one-way analysis of variance coupled with Bonferroni's or Dunnett's post hoc test. In non-Gaussian distributed variables, the statistical significance between groups was determined using Mann-Whitney test or Kruskal-Wallis test coupled with Dunn's post hoc test. Linear regression was performed to analyze the timedependent evolution of DNA fragmentation. Tests were considered significant when $P$-values were $\leqslant 0.05$ 
Acknowledgements. Julien Daubriac is a fellow of the French Ministry of Research and the Fondation pour la Recherche Médicale.

This work was supported by funding from INSERM and by Grants from the Ligue Nationale Contre le Cancer (comité de l'Oise, France), R07103HH; the Agence Nationale de la Recherche 059 31/ANR 05 SEST029-01; and the Agence Française de Sécurité Sanitaire de l'Environnement et du Travail RD-2004-015.

We thank Professor JF Bernaudin (Hôpital Tenon) and his laboratory for their help with the flow cytometry and cytochemistry experiments, Professor $\mathrm{P}$ Astoul (Hôpital de la Conception, Marseille), Professor JC Pairon (CHI Créteil), Dr. I Abd Al Samad (CHI Créteil), and the MesoPath Register for accessing the data concerning mesothelioma patients, IFR65/UPMC for TEM experiments, and Drs. D Lallemand (INSERM U674), H Feracci (CRPP) and P Codogno (INSERM U756) for their critical reading of the manuscript and stimulating scientific discussions.

1. Robinson BW, Musk AW, Lake RA. Malignant mesothelioma. Lancet 2005; 366: 397-408.

2. Craighead J, Kane A. The pathogenesis of malignant and nonmalignant serosal lesions in body cavities consequent to asbestos exposure. In: Jaurand MC, Bignon J (eds). The mesothelial cell and mesothelioma. Marcel Dekker: New York, Basel, Hong Kong, 1994, pp 79-102.

3. van der Kwast T, Delahaye M, Fleury J. Cytological diagnosis of malignant mesothelioma In: Jaurand MC, Bignon J (eds). The mesothelial cell and mesothelioma. Marcel Dekker New York, Basel, Hong Kong, 1994, pp 121-168.

4. Whitaker D. The cytology of malignant mesothelioma. Cytopathology 2000; 11: 139-151

5. Frisch SM, Screaton RA. Anoikis mechanisms. Curr Opin Cell Biol 2001; 13: 555-562.

6. Zeng Q, Chen S, You Z, Yang F, Carey TE, Saims D et al. Hepatocyte growth factor inhibits anoikis in head and neck squamous cell carcinoma cells by activation of erk and akt signaling independent of nfkappa b. J Biol Chem 2002; 277: 25203-25208.

7. Collins NL, Reginato MJ, Paulus JK, Sgroi DC, Labaer J, Brugge JS. G1/s cell cycle arrest provides anoikis resistance through erk-mediated bim suppression. Mol Cell Biol 2005; 25: 5282-5291.

8. Marani M, Hancock D, Lopes R, Tenev T, Downward J, Lemoine NR. Role of bim in the survival pathway induced by raf in epithelial cells. Oncogene 2004; 23: 2431-2441.

9. Diaz-Montero CM, Wygant JN, McIntyre BW. Pi3-k/akt-mediated anoikis resistance of human osteosarcoma cells requires src activation. Eur J Cancer 2006; 42: 1491-1500.

10. Windham TC, Parikh NU, Siwak DR, Summy JM, McConkey DJ, Kraker AJ et al. Src activation regulates anoikis in human colon tumor cell lines. Oncogene 2002; 21: 7797-7807.

11. Wei L, Yang Y, Zhang X, Yu Q. Altered regulation of src upon cell detachment protects human lung adenocarcinoma cells from anoikis. Oncogene 2004; 23: 9052-9061.

12. Plotkin LI, Manolagas SC, Bellido T. Glucocorticoids induce osteocyte apoptosis by blocking focal adhesion kinase-mediated survival. Evidence for inside-out signaling leading to anoikis. J Biol Chem 2007; 282: 24120-24130.

13. Li AE, Ito H, Rovira II, Kim KS, Takeda K, Yu ZY et al. A role for reactive oxygen species in endothelial cell anoikis. Circ Res 1999; 85: 304-310.

14. Reed BH, Wilk R, Schîck F, Lipshitz HD. Integrin-dependent apposition of drosophila extraembryonic membranes promotes morphogenesis and prevents anoikis. Curr Biol 2004; 14: 372-380.

15. Leard LE, Broaddus VC. Mesothelial cell proliferation and apoptosis. Respirology 2004; 9 292-299.

16. Fennell DA, Rudd RM. Defective core-apoptosis signalling in diffuse malignan pleural mesothelioma: opportunities for effective drug development. Lancet Oncol 2004; 5: 354-362.

17. Altomare DA, You H, Xiao G-H, Ramos-Nino ME, Skele KL, De Rienzo A et al. Human and mouse mesotheliomas exhibit elevated akt/pkb activity, which can be targeted pharmacologically to inhibit tumor cell growth. Oncogene 2005; 24: 6080-6089.

18. Bertino P, Marconi A, Palumbo L, Bruni BM, Barbone D, Germano S et al. Erionite and asbestos differently cause transformation of human mesothelial cells. Int J Cancer 2007 121: $12-20$.

19. Catalano A, Rodilossi S, Rippo MR, Caprari P, Procopio A. Induction of stem cell factor/ c-kit/slug signal transduction in multidrug-resistant malignant mesothelioma cells. J Bio Chem 2004; 279: 46706-46714
20. Ramos-Nino ME, Vianale G, Sabo-Attwood T, Mutti L, Porta C, Heintz N et al. Human mesothelioma cells exhibit tumor cell-specific differences in phosphatidylinositol 3-kinase/ akt activity that predict the efficacy of onconase. Mol Cancer Ther 2005; 4: 835-842.

21. de Melo M, Gerbase MW, Curran J, Pache JC. Phosphorylated extracellular signalregulated kinases are significantly increased in malignant mesothelioma. $J$ Histochem Cytochem 2006; 54: 855-861.

22. Cole GW, Alleva AM, Zuo JT, Sehgal SS, Yeow W-S, Schrump DS et al. Suppression of pro-metastasis phenotypes expression in malignant pleural mesothelioma by the pi3k inhibitor ly294002 or the mek inhibitor u0126. Anticancer Res 2006; 26: 809-821.

23. Mukohara T, Civiello G, Davis IJ, Taffaro ML, Christensen J, Fisher DE et al. Inhibition of the met receptor in mesothelioma. Clin Cancer Res 2005; 11: 8122-8130.

24. Vivo C, Liu W, Broaddus VC. C-jun n-terminal kinase contributes to apoptotic synergy induced by tumor necrosis factor-related apoptosis-inducing ligand plus DNA damage in chemoresistant, p53 inactive mesothelioma cells. J Biol Chem 2003; 278: 25461-25467.

25. Bedrossian CW, Bonsib S, Moran C. Differential diagnosis between mesothelioma and adenocarcinoma: A multimodal approach based on ultrastructure and immunocytochemistry. Semin Diagn Pathol 1992; 9: 124-140.

26. Kim KL, Wilson SM, Abayasiriwardana KS, Collins R, Fjellbirkeland L, Xu ZD et al. A novel in vitro model of human mesothelioma for studying tumor biology and apoptotic resistance. Am J Respir Cell Mol Biol 2005; 33: 541-548.

27. Zhang Z, Cao L, Li J, Liang X, Liu Y, Liu H et al. Acquisition of anoikis resistance reveals a synoikis-like survival style in bel7402 hepatoma cells. Cancer Lett 267: 106-115.

28. Aplin AE, Howe A, Alahari SK, Juliano RL. Signal transduction and signal modulation by cell adhesion receptors: The role of integrins, cadherins, immunoglobulin-cell adhesion molecules, and selectins. Pharmacol Rev 1998; 50: 197-263.

29. Barbone D, Yang T-M, Morgan JR, Gaudino G, Broaddus VC. Mammalian target of rapamycin contributes to the acquired apoptotic resistance of human mesothelioma multicellular spheroids. J Biol Chem 2008; 283: 13021-13030.

30. Daubriac J, Fleury-Feith J, Jaurand MC. Anoikis resistance in malignant pleural mesothelioma cells. Lung Cancer 2006; 54: S24.

31. Yang J-M, O'Neill $P$, Jin W, Foty R, Medina DJ, Xu Z et al. Extracellular matrix metalloproteinase inducer (cd147) confers resistance of breast cancer cells to anoikis through inhibition of bim. J Biol Chem 2006; 281: 9719-9727.

32. Puthalakath H, Huang DC, O'Reilly LA, King SM, Strasser A. The proapoptotic activity of the bcl-2 family member bim is regulated by interaction with the dynein motor complex. Mol Cell 1999; 3: 287-296.

33. Strasser A, Puthalakath $\mathrm{H}$, Bouillet $\mathrm{P}$, Huang DC, O'Connor L, O'Reilly LA et al. The role of bim, a proapoptotic bh3-only member of the bcl-2 family in cell-death control. Ann NY Acad Sci 2000; 917: 541-548

34. Lei K, Davis RJ. Jnk phosphorylation of bim-related members of the bcl2 family induces bax-dependent apoptosis. Proc Natl Acad Sci USA 2003; 100: 2432-2437.

35. Abayasiriwardana KS, Barbone D, Kim K-U, Vivo C, Lee KK, Dansen TB et al. Malignant mesothelioma cells are rapidly sensitized to trail-induced apoptosis by low-dose anisomycin via bim. Mol Cancer Ther 2007; 6: 2766-2776.

36. Shen X, Kramer RH. Adhesion-mediated squamous cell carcinoma survival through ligandindependent activation of epidermal growth factor receptor. Amer J Pathol 2004; 165: $1315-1329$

37. Davidson B. Biological characteristics of cancers involving the serosal cavities. Crit Rev Oncog 2007; 13: 189-227.

38. Reginato MJ, Mills KR, Paulus JK, Lynch DK, Sgroi DC, Debnath J et al. Integrins and egfr coordinately regulate the pro-apoptotic protein bim to prevent anoikis. Nat Cell Biol 2003; 5 : 733-740.

39. Rump A, Morikawa Y, Tanaka M, Minami S, Umesaki N, Takeuchi M et al. Binding of ovarian cancer antigen ca125/muc16 to mesothelin mediates cell adhesion. J Biol Chem 2004; 279: 9190-9198.

40. Uehara N, Matsuoka Y, Tsubura A. Mesothelin promotes anchorage-independent growth and prevents anoikis via extracellular signal-regulated kinase signaling pathway in human breast cancer cells. Mol Cancer Res 2008; 6: 186-193.

41. Willis SN, Adams JM. Life in the balance: How bh3-only proteins induce apoptosis. Curr Opin Cell Biol 2005; 17: 617-625.

42. Zeng L, Fleury-Feith J, Monnet I, Boutin C, Bignon J, Jaurand MC. Immunocytochemical characterization of cell lines from human malignant mesothelioma: Characterization of human mesothelioma cell lines by immunocytochemistry with a panel of monoclonal antibodies. Hum Pathol 1994; 25: 227-234.

Supplementary Information accompanies the paper on Cell Death and Differentiation website (http://www.nature.com/cdd) 